\title{
Testing for Over-Reaction and Under-Reaction in Chinese Shanghai Composite Index Constituent Stocks and Australian Resource Stocks
}

\author{
Santosh Mon Abraham ${ }^{1}$ \\ ${ }^{1}$ School of Economics and Finance, Curtin University, Australia \\ Correspondence: Santosh Mon Abraham, School of Economics and Finance, Curtin University, Bentley, W.A., \\ 6845, Australia. Email: santosh.monabraham@gmail.com
}

Received: August 6, 2013

Accepted: September 5, 2013 Online Published: September 26, 2013

doi:10.5539/ijef.v5n10p51

URL: http://dx.doi.org/10.5539/ijef.v5n10p51

\begin{abstract}
This paper describes a new formulation of the partial adjustment model (PAM) and its speed of adjustment coefficient. Speed of adjustment coefficients have been used to measure the efficiency or inefficiency in financial markets. Using the model by Amihud and Mendelson (1987), Damodaran (1993) and Brisely and Theobald (1996) and Theobald and Yallop (2004) have developed speed of adjustment coefficients for this purpose. Whilst their formulation suffers from non-synchronous problems, the formulation of the new PAM in this paper avoids such problems. The new PAM is used to measure the efficiency of CSC constituent stocks and Australian resource stocks. In both categories, some stocks over-react, some under-react and some fully adjust to new economic information and are efficient.
\end{abstract}

Keywords: efficient markets, partial adjustment models, China and Australia

\section{Introduction}

In an efficient market, observed price should include new information to reflect changes to its fundamental value. Such an adjustment should be immediate if the market is strongly efficient (Fama, 1991). Thus the adjustment speed of stock price to the changed fundamental value due to economic news determines the degree of efficiency in the stock market (Marisetty, 2003).

The literature of over-reactions (for example, DeBondt \& Thaler, 1985, 1987), under-reactions (for example, Michaely et al., 1995; Bernard \& Thomas, 1989) and other anomalies (for example, Jegadeesh and Titman, 1993, 2001) has led to a search for alternative theoretical models to describe the price adjustment process. Behavioural models have been subsequently developed to justify the under (over) reaction hypotheses (for example Barberis et al. 1998, Daniel et al. 1998; Hong \& Stein 1999; Fama 1998). Differences exist in ways to measure the speed at which stocks adjust. Often, an event study is used to ascertain the dynamics of pricing around the time of a macroeconomic shock. However, speed is only determined for a predefined known event (Boulter, 2007). Amihud and Mendelson (1987) propose a model of price adjustment in which observed prices adjust towards their intrinsic values. A number of estimators have been subsequently developed in the literature. Damodaran (1993) and Brisley and Theobald (1996) estimate the speed of adjustment using the partial adjustment model. Theobald and Yallup (2004) compare the speed of price adjustments between large and small companies (Jang, 2009).

The purpose this paper is to estimate speed of adjustment within a new partial adjustment model (PAM), in order to investigate the efficiency of the Chinese Shanghai Composite index constituent stocks and the Australian resources stocks. The results have many implications for both researchers and practitioners. First, the price adjustment process in Chinese and Australian markets is mixed. Some stocks over-react, some under-react and some fully adjust to new economic information. Second, price over-reaction and under-reaction indicates inefficiencies in the information dissemination process in these markets. Third, the PAM demonstrates that these inefficiencies are short-term and that in the long-term there is equilibrium and the markets are efficient.

Since the reforms of 1978, China has financially deregulated and liberalised its market. However, China's financial system is still highly regulated. As a result, the Chinese and Australian financial markets cannot be fairly compared. China has recognised the dangers of a completely free global financial market without first having strong institutions. However, there is a strong impetus for China to open its doors more widely to the 
outside world, allowing foreign firms to engage in financial services. Further liberalisation is occurring in financial markets and in the future it is expected that the Chinese financial market will be more open and comparable with Australian markets.

\subsection{Review of Relevant Literature}

Black (1986) stated that the stock price consists of two factors, noise and the intrinsic value. Noise is intrinsic value minus the observed price. Amihud and Mendelson (1986) reduced the variance of noise into two parts; the intrinsic value variance which is the result of dissimilar valuations due to heterogeneous beliefs among investors and that which is the result of pure noise due to irrational behaviour. Amihud and Mendelson (1987) state that stock prices tend towards fundamentals by way of price adjustment such that (Marisetty, 2003):

$$
P_{t}-P_{t-1}=g\left(V_{t}-P_{t-1}\right)+\mu_{t}
$$

where $\left(V_{t}\right)$ and $\left(P_{t}\right)$ are in logarithms. $\left(P_{t}-P_{t-1}\right)$ is the observed price change, $\left(V_{t}-P_{t-1}\right)$ represents the information-induced change in price which adjusts by $(g)$ which with value 1 represents full price adjustment towards the intrinsic value. The value of $g$ between $0<g<1$ represents partial adjustment towards the intrinsic value. $g$ with value 0 represents no adjustment and $g>1$ represents over-reaction of the price towards change in the intrinsic value to economic news (Marisetty, 2003).

Damodaran (1993) extended Amihud and Mendelsohn's (1986) model by measuring the speed of adjustment of stocks in response to macroeconomic shocks. He makes the assumption that speed of adjustment is not immediate. Damodaran (1993) divided time into daily units. He also assumes that the maximum time for price adjustment is 20 days based on experimental data. He derived his estimator from reducing the observed return variance into three parts (Marisetty, 2003; Boulter, 2007):

$$
\begin{gathered}
\operatorname{Var}\left(R_{t}\right)=v^{2}+2 \sigma^{2}+\left[\left(\frac{g}{2-g}-1\right) v^{2}+\left(\frac{2}{2-g}-2\right) \sigma^{2}\right] \\
v^{2}+2 \sigma^{2} \\
{\left[\left(\frac{g}{2-g}-1\right) v^{2}+\left(\frac{2}{2-g}-2\right) \sigma^{2}\right]}
\end{gathered}
$$

Where $\left(v^{2}\right)$ is the variance of the intrinsic value, $\left(2 \sigma^{2}\right)$ is the noise variance, and (4) is the variance relating to the price adjustment process (Boulter, 2007).

The estimator $(g)$ arises from observed return variances that are calculated over different time intervals. Thus $\left(R_{j t}\right)$ would be the return in time period $(t)$ in which the return interval is $(j)$ (Boulter, 2007). The variance:

$$
\operatorname{Var}\left(R_{j t}\right)=\left[\frac{g_{j}}{2-g_{j}} j v^{2}+\frac{2}{\left(2-g_{j}\right)} \sigma^{2}\right]
$$

It is assumed that an amount of return unit-intervals are enough to calculate the variances, so that $(j=1,2, \ldots k)$, and that the limiting interval $(k)$ is enough to allow $(g)$ to equal one, allowing the variances in $(j)$ and in $(k)$ interval returns to be as follows (Boulter, 2007).

$$
\operatorname{Var}\left(R_{j t}\right)-\frac{\operatorname{Var}\left(R_{k t}\right)}{k}=v^{2}\left[\frac{g_{j}}{\left(2-g_{j}\right)}-1\right]+2 \sigma^{2}\left[\frac{1}{\left(2-g_{j}\right)}-\frac{1}{k}\right]
$$

where $\left(v^{2}\right)$ and $\left(\sigma^{2}\right)$ are functions of the covariance and variance in $(k)$ intervals as follows:

$$
\begin{gathered}
v^{2}=\frac{\operatorname{Var}\left(R_{k t}\right)+2 \operatorname{Cov}\left(R_{k t}, R_{k t-1}\right)}{k} \\
\sigma^{2}=-\operatorname{Cov}\left(R_{k t}, R_{k t-1}\right)
\end{gathered}
$$

Substituting $\left(v^{2}\right)$ and $\left(\sigma^{2}\right)$, in equation (5), and solving for $(g)$, Damodaran's estimate of the speed of adjustment is as follows (Boulter, 2007):

$$
g=\frac{\frac{\operatorname{Var}\left(R_{j, t}\right)}{j}+\frac{\operatorname{Var}\left(R_{k, t}\right)}{k}(j-1)+\frac{\operatorname{Cov}\left(R_{k, t}, R_{k, t-1}\right)}{j}}{\frac{\operatorname{Var}\left(R_{j, t}\right)}{j}+\frac{\operatorname{Var}\left(R_{k, t}\right)}{k}(2 j-1)+\frac{2 \operatorname{Cov}\left(R_{k, t}, R_{k, t-1}\right)}{k}}
$$

If the market is efficient, then the faster $(g)$ should converge to (1). Brisley and Theobald (1996) find an error within Damodaran's calculation which they correct. Their estimator is as follows (Boulter, 2007): 


$$
g=\frac{\frac{2\left[\operatorname{Var}\left(R_{j, t}\right)\right.}{j}+\frac{\left.2 \operatorname{Cov}\left(R_{k, t}, R_{k, t-1}\right)\right]}{j}}{\frac{\operatorname{Var}\left(R_{j, t}\right)}{j}+\frac{\operatorname{Var}\left(R_{k, t}\right)}{k}+\frac{2 \operatorname{Cov}\left(R_{k, t}, R_{k, t-1}\right)}{k}}
$$

The Damodaran (1993) estimator overstates the price response towards intrinsic value when adjustment is incomplete (Boulter, 2007). When the interval $(j)$ approaches $(k)$, the errors within the numerator and denominator increasingly dominate the equation, forcing the speed of adjustment coefficient towards one. The Brisley and Theobald (1996) derive an estimator that adjusts for this error.

Theobold and Yallup (2004) construct two estimators without the use a limiting interval, which assume a lagged price response caused by traders initially under or over-reacting to information (Boulter, 2007).

Partial adjustment may be caused by non-synchronous trading as pointed out by Lo and MacKinlay (1990). They state that the speed of adjustment is a function of the autocorrelation and cross-autocorrelation terms within returns, caused by trading that is which is cyclical due to recurrences in trading activity. The under-reaction of stock prices will cause the series will be positively correlated and the over-reaction results in negative correlation. The time taken for intrinsic value to adjust is how long it takes to allow the positive or negative autocorrelation within the observed return series to dissolve.

Theobold and Yallup (2004) state that auto-covariances for lags one and two can be derived as:

$$
\operatorname{Cov}\left\{R_{t}, R_{t-1}\right\}=\frac{g}{2-g}\left[(1-g) v^{2}-\sigma^{2}\right]
$$

and lag two (-2) as:

$$
\operatorname{Cov}\left\{R_{t}, R_{t-2}\right\}=g \frac{(1-g)}{2-g}\left[(1-g) v^{2}-\sigma^{2}\right]
$$

Since the cross-covariance between them are zero at all lags, the coefficient $(g)$ may be expressed as a function of the auto-covariance structure:

$$
1-g=\frac{\operatorname{Cov}\{R(t), R(t-2)\}}{\operatorname{Cov}\{R(t), R(t-1)\}}
$$

The auto-covariance estimator is easy to estimate. A problem is the effect of non-synchronous trading. This occurs when thin trading occurs prices do not change over a long time, which leads to runs of zeros within the return series. This could result in autocorrelation that is distinct from traders under or over-reaction to information (Boulter, 2007).

\subsection{The New Partial Adjustment Model}

The PAM assumes the long-run equilibrium equation is given by the single-index model:

$$
R_{t}=a+\beta R_{m}+e
$$

Where $R_{t}$ is the target return; $a$ is the excess return; $B$ is the sensitivity of the stock to the market, $R_{m}$ is the market return; and e is the residual.

Similar to the model of Amihud and Mendelson (1987), the impact from noise trading is the difference between the fundamental return and the observed return.

The following hypothesis known as the PAM is postulated:

$$
\begin{gathered}
R_{t}-R_{t-1}=\delta\left(R_{t}-R_{t-1}\right) \\
R_{t}-R_{t-1}=\delta\left(\left(a+\beta R_{m}+e\right)-R_{t-1}\right) \\
R_{t}=\delta a+\delta \beta R_{m}+(1-\delta) R_{t-1}+\delta e \\
R_{t}=\delta a+\delta \beta R_{m}+(1-\delta) \beta R_{m_{t-1}}+\delta e
\end{gathered}
$$

Where $R_{t}$ is the return in time period $t, R_{t-1}$ is the return in time period $t-1, \delta$ is the speed of adjustment coefficient and $\mathrm{e}$ is the error term $\mathrm{E}[\mathrm{e}]=0$ and $\mathrm{E} \sim \mathrm{N}\left(0, \sigma^{2}\right)$. When $\delta$ equals 0 there is no adjustment, when $\delta$ equals 1 there is full adjustment and the market is efficient, when $\delta$ is greater than 1 there is an over-reaction to economic information and when $\delta$ lies between 0 and 1 there is partial adjustment or under-reaction to economic information.

There should be no opportunity to use information gathered in period t-1 to provide a correct assessment of the expected return. The information available at $\mathrm{t}-1$, the time series of past returns, should not be able to be used to 
correctly determine the expected return. By using past information in this way makes this approach a test of weak form market efficiency. If the variance of $\mathrm{e}$ is high then that would be evidence against weak form market efficiency, in addition to the value of the speed of adjustment.

The first step is to calculate the alpha (excess return) and beta (systematic risk) by regression the stock's return against the market return. The beta is multiplies by the market return and added to alpha. The proxy used for the lagged return is $\beta R_{m(t-1)}$. The stochastic explanatory variable $R_{t-1}$ may be correlated with the error term, which would make the OLS estimator biased and inconsistent so that the estimates would not approximate their true population values. This correlation can be removed by finding a suitable proxy for $R_{t-1}$. Such a proxy is $\beta R_{m(t-1)}$.

The single-index model is used in the PAM instead of a multi-factor model because the object of the PAM is to calculate the speed of adjustment coefficient. A multi-factor model would introduce too many terms in the PAM and would lead to difficulties in finding an appropriate proxy for $\mathrm{R}_{\mathrm{t}-1}$.

There is no autocorrelation or auto-covariance structure in this formulation of the PAM. It therefore avoids the problem of nonsynchronous or infrequent trading that effect many of the other models which estimate the speed of adjustment.

\section{Method}

The sample consists of 533 weekly observations from 1 Jan 2003 to 1 Mar 2013 of the Chinese Shanghai Composite Index and 33 Australian Resource stocks. All variables were converted to natural logarithms. The financial data was collected from Yahoo Finance.

\section{Results}

Table 1 shows the diagnostics of the PAM.

Table 1. The diagnostics of the partial adjustment model

\begin{tabular}{|c|c|c|c|c|c|c|c|c|c|}
\hline STOCK & COEFF & $\mathrm{t}-$ Stat & R-SQR & DW & STOCK & COEFF & $\mathrm{t}-$ Stat & R-SQR & DW \\
\hline 600519.ss & -0.06635 & -1.44072 & 0.032405 & 2.546665 & NCM.AX & -0.56368 & -6.68554 & 0.016583 & 2.426353 \\
\hline 600583.ss & -0.03076 & -1.02931 & 0.044919 & 2.079458 & OGC.AX & -0.07514 & -1.75907 & 0.001275 & 1.990348 \\
\hline $600050 . s s$ & -0.01269 & -0.8975 & 0.235009 & 1.994056 & MDL.AX & -0.04556 & -0.50602 & 0.000107 & 1.983126 \\
\hline 600018.SS & -0.00784 & -0.26498 & 0.049202 & 1.933736 & GDO.AX & -0.04175 & -0.10994 & 0.03068 & 1.436451 \\
\hline 600016.SS & -0.00712 & -0.4774 & 0.355705 & 1.986318 & KCN.AX & -0.0306 & -0.66951 & 0.000281 & 1.975596 \\
\hline 600879.ss & 0.021735 & 1.057289 & 0.092408 & 1.945672 & AGG.AX & -0.01143 & -0.7894 & 0.000245 & 2.262396 \\
\hline 600036.SS & .003 & -0.24223 & 0.462789 & 2.052398 & AAI.AX & -0.00767 & -0.51201 & 0.002521 & 2.108659 \\
\hline 600000.SS & $.21 \mathrm{E}-17$ & -0.79028 & 1 & 1.981371 & SBM.AX & -0.0073 & -0.13522 & 0.002402 & 2.442574 \\
\hline 600642.ss & 0.013576 & 0.825776 & 0.150931 & 1.974525 & CDU.AX & -0.00323 & -0.07279 & 0.000717 & 1.983054 \\
\hline 600037.ss & 0.003705 & 0.193506 & 0.112075 & 1.929668 & RRL.AX & -0.00172 & -0.05083 & 0.001636 & 2.023806 \\
\hline 600795.ss & 0.022067 & 2.170131 & 0.445671 & 1.954692 & IGO.AX & 0.001197 & 0.038107 & 0.002755 & 2.045536 \\
\hline 601600.ss & 0.074653 & 4.453399 & 0.145518 & 1.925693 & & 0.007957 & 0.203515 & 0.000298 & 2.137731 \\
\hline 60033 & 61 & & 0.05 & 1.96 & $\mathrm{BH}$ & 0.008888 & 4902 & 0.016881 & 2.092183 \\
\hline 600688.ss & 0.041387 & 2.283704 & 0.125279 & 1.80875 & MGX.AX & 0.010172 & 0.476272 & 0.005139 & 2.000023 \\
\hline 600832.ss & -0.00571 & -0.28819 & 0.090846 & 1.980106 & S.AX & 0.010207 & 78675 & 0.000342 & 2.02444 \\
\hline 600028.SS & 0.020931 & 1.5681 & 0.249952 & 1.987171 & IGR.AX & 0.010456 & 0.219221 & 0.002899 & 2.213796 \\
\hline 600104.ss & 0.021224 & 1.219567 & 0.14363 & 1.963668 & & 0.011292 & 0.403605 & 0.004726 & 2.129354 \\
\hline 600887.ss & 0.00 & & 0.07 & & & 4483 & 774 & 0354 & 1.998599 \\
\hline 600811.ss & 0205 & 9724 & 57 & 1.896156 & PNA.AX & 0.014727 & 289 & 0.001281 & 2.005987 \\
\hline 600100.ss & 0.026794 & 368446 & 0.099737 & 2.011594 & ARI.AX & 0.01512 & 0.899238 & 0.008397 & 2.108659 \\
\hline 600009.SS & 0.029477 & 79053 & 0.177301 & 1.919847 & AQP.AX & 0.019917 & 183306 & 0.016273 & 1.945965 \\
\hline 600011.SS & 0.03002 & 1.716363 & 0.130375 & 1.918208 & BSL.AX & 0.022004 & 0.903593 & 0.001078 & 1.960833 \\
\hline 600269.ss & 0.033465 & 2.489689 & & & GBG.AX & 0.023421 & 0.927618 & 0.006369 & 2.132077 \\
\hline 600005.SS & & & & & & & & 6125 & 1.947409 \\
\hline 600026.SS & 35863 & 704828 & 0.239411 & 1.914828 & OZL.AX & 0.044024 & 1.962422 & 0.013189 & 2.066952 \\
\hline 600111.ss & 0.040196 & 1.806807 & 0.076551 & 2.057708 & SGM.AX & 0.044598 & 0.355612 & 0.002634 & 2.07253 \\
\hline 600717.ss & 0.006255 & 0.30894 & 0.129601 & 2.049608 & IMD.AX & 0.060852 & 2.052789 & 0.006355 & 1.995376 \\
\hline 600177.ss & 0.045696 & 2.542071 & 0.166572 & 2.003923 & IRN.AX & 0.06988 & 1.460731 & 0.00259 & 2.126806 \\
\hline 600309.ss & 0.050824 & 2.476643 & 0.106353 & 1.924252 & EVN.AX & 0.083956 & 2.025263 & 0.002926 & 2.155215 \\
\hline 600362.ss & & & & & & & & & 1.96512 \\
\hline 600019.SS & & & & & & & 1.374927 & 0.002429 & 2.10072 \\
\hline $600320 . s s$ & 0.060 & 597692 & 0.084937 & 2.068515 & SIR.AX & 0.104174 & 2.051616 & 0.003681 & 2.044306 \\
\hline 600601.ss & 0.003077 & 0.170727 & 0.123513 & 2.011847 & WSA.AX & 0.104422 & 0.556284 & 0.000178 & 2.135877 \\
\hline
\end{tabular}

Note: COEFF means coefficient; t-Stat means t-statistic; R-SQR means R ${ }^{2}$ coefficient; DW means Durbin-Watson.

The Table 5 shows that the results were not significant for the following stocks: $600019 ; 600026 ; 600177$; 600269; 600309; 600320; 600362; 600688; 600795; 601600; EVN.AX; GRR.AX; IMD.AX; NCM.AX; 
OZL.AX; SIR.AX.

Table 2 shows the results of the speed of adjustment coefficients for Chinese and Australian stocks.

Table 2. The speeds of adjustments for the CSC constituent stocks and Australian resources stocks

\begin{tabular}{|c|c|c|c|c|c|c|c|}
\hline STOCK & SPEED & BETA & MCAP(mil) & STOCK & SPEED & BETA & MCAP(mil) \\
\hline 600519.ss & 1.066353 & 1.069409 & $\$ 26,386.08$ & NCM.AX & 1.563677 & 1.153444 & $\$ 14,399.05$ \\
\hline 600583.ss & 1.030761 & 1.06963 & $\$ 3,867.24$ & OGC.AX & 1.075138 & 1.194804 & $\$ 1,362.91$ \\
\hline $600050 . s s$ & 1.012694 & 0.829947 & $\$ 12,033.81$ & MDL.AX & 1.045558 & 1.066206 & $\$ 275.68$ \\
\hline 600018.SS & 1.007835 & 1.124973 & $\$ 9,494.85$ & GDO.AX & 1.041748 & 0.810438 & $\$ 339.97$ \\
\hline 600016.SS & 1.007121 & 0.581978 & $\$ 40,444.84$ & KCN.AX & 1.030601 & 0.991805 & $\$ 531.40$ \\
\hline 600879.ss & 1.005713 & 1.263689 & $\$ 1,123.44$ & AGG.AX & 1.011431 & 1.425217 & $\$ 1,831.00$ \\
\hline 600036.SS & 1.002997 & 1.290845 & $\$ 42,476.33$ & AAI.AX & 1.00767 & 0.133171 & $\$ 8,500.00$ \\
\hline 600000.SS & 1.000000 & 1.062374 & $\$ 29,108.07$ & SBM.AX & 1.007299 & 1.45542 & $\$ 514.92$ \\
\hline 600642.ss & 0.996923 & 1.110974 & $\$ 3,293.45$ & CDU.AX & 1.003231 & 0.299662 & $\$ 663.59$ \\
\hline 600037.ss & 0.996295 & 0.816957 & $\$ 1,051.03$ & RRL.AX & 1.001721 & 0.268901 & $\$ 1,878.68$ \\
\hline 600795.ss & 0.993745 & 1.15492 & $\$ 7,910.94$ & IGO.AX & 0.998803 & 0.838099 & $\$ 859.34$ \\
\hline 601600.ss & 0.992643 & 1.359832 & $\$ 7,473.80$ & SPH.AX & 0.992043 & 1.794434 & $\$ 676.63$ \\
\hline 600331.ss & 0.991439 & 1.029045 & $\$ 872.43$ & BHP.AX & 0.991112 & 0.63847 & $\$ 161,632.00$ \\
\hline 600688.ss & 0.986424 & 1.114578 & $\$ 5,543.39$ & MGX.AX & 0.989828 & 1.083146 & $\$ 512.57$ \\
\hline 600832.ss & 0.9795 & 0.829772 & $\$ 2,698.61$ & RSG.AX & 0.989793 & 1.435691 & $\$ 729.91$ \\
\hline 600028.SS & 0.979069 & 1.062374 & $\$ 104,374.24$ & IGR.AX & 0.989544 & 0.876141 & $\$ 485.90$ \\
\hline 600104.ss & 0.978776 & 0.839762 & $\$ 25,140.50$ & LYC.AX & 0.988708 & 0.996607 & $\$ 1,009.81$ \\
\hline 600887.ss & 0.978265 & 0.885271 & $\$ 8,758.22$ & SDL.AX & 0.985517 & 1.530724 & $\$ 645.14$ \\
\hline 600811.ss & 0.977933 & 1.158478 & $\$ 1,484.06$ & PNA.AX & 0.985273 & 1.334658 & $\$ 1,406.99$ \\
\hline 600100.ss & 0.973206 & 0.837848 & $\$ 2,139.77$ & ARI.AX & 0.98488 & 0.566847 & $\$ 1,020.40$ \\
\hline 600009.SS & 0.970523 & 0.996509 & $\$ 3,945.50$ & AQP.AX & 0.980083 & 0.555988 & $\$ 316.00$ \\
\hline 600011.SS & 0.96998 & 1.269564 & $\$ 14,692.24$ & BSL.AX & 0.977996 & 0.76673 & $\$ 2,651.66$ \\
\hline 600269.ss & 0.966535 & 0.892821 & $\$ 1,231.68$ & GBG.AX & 0.976579 & 0.788386 & $\$ 283.51$ \\
\hline 600005.SS & 0.965442 & 1.096068 & $\$ 4,305.68$ & TRY.AX & 0.969256 & 1.808882 & $\$ 173.96$ \\
\hline 600026.SS & 0.964137 & 0.977953 & $\$ 1,969.20$ & OZL.AX & 0.955976 & 1.33193 & $\$ 1,440.00$ \\
\hline 600111.ss & 0.959804 & 0.84184 & $\$ 10,891.46$ & SGM.AX & 0.955402 & 1.680748 & $\$ 1,936.85$ \\
\hline 600717.ss & 0.958613 & 1.128586 & $\$ 1,563.89$ & IMD.AX & 0.939148 & 0.942622 & $\$ 271.51$ \\
\hline 600177.ss & 0.954304 & 1.148483 & $\$ 2,676.71$ & IRN.AX & 0.93012 & 0.980166 & $\$ 409.07$ \\
\hline 600309.ss & 0.949176 & 1.035379 & $\$ 6,034.06$ & EVN.AX & 0.916044 & 0.786781 & $\$ 902.82$ \\
\hline 600362.ss & 0.943443 & 1.032142 & $\$ 10,341.67$ & GRR.AX & 0.897727 & 0.819006 & $\$ 219.73$ \\
\hline 600019.SS & 0.942489 & 1.091093 & $\$ 12,881.11$ & RIO.AX & 0.896701 & 1.335901 & $\$ 85,933.67$ \\
\hline 600320.ss & 0.93989 & 1.010157 & $\$ 1,965.18$ & SIR.AX & 0.895826 & 1.682214 & $\$ 788.42$ \\
\hline 600601.ss & 0.925347 & 0.923437 & $\$ 796.68$ & WSA.AX & 0.895578 & 1.742187 & $\$ 574.78$ \\
\hline
\end{tabular}

Note: STOCK is the Chinese and Australian stock, BETA is systematic risk, MCAP is market capitalisation, SPEED is the speed of adjustment coefficient from the PAM.

Table 2 show that the 33 Australian and Chinese financial stocks are ranked in order from the fastest speed of adjustment to the slowest speed of adjustment. The fastest Chinese and Australian stocks are 600519.ss and NCM.AX, with speeds of 1.07 and 1.56, which is followed by 600583.ss and OGC.AX with speeds of 1.03 and 1.08. The slowest speeds of adjustment are 600601.ss and WSA.AX with speeds of 0.92 and 0.90 . The second slowest 9and third slowest are 600320.ss (0.94) and SIR.AX (0.90) and 600019.ss (0.94) and RIO.AX (0.90) respectively.

It may be recalled that a speed of adjustment of 1 means the stocks fully adjust to new information and that they are efficient. A speed greater than 1 means the stocks over-react and a speed of $0<\delta<1$ means the stock under-react. Remember that over-reaction leads to contrarian strategies and that under-reaction leads to momentum strategies. Thus both contrarian and momentum strategies should be profitable in this sample. Small cap stocks tended to over-react and under-react and thus were inefficient. Large and medium cap stocks tended to fully adjust and thus were efficient.

\section{Discussion}

In this paper a new PAM was developed which does not suffer from the problem of non-synchronous trading because it does not make use of auto-correlation structures in its formulation. The new measure reports that for both Chinese and Australian markets there are short-term inefficiencies. These occur mainly in small cap stocks which under-react and over-react to new economic information. By the very nature of the PAM there is a long-term equilibrium. Therefore markets are efficient in the long-term.

Out of sixty-six stocks in table two, seven Chinese and ten Australian stocks have (g) greater than one. This does not provide overwhelming evidence of overreaction of the prices in response to the arrival of new information. 
Twenty-five Chinese and twenty-three Australian stocks have g less than one, suggesting under reaction or slow adjustment process. The results indicate that speed of adjustment is quite slow in China and Australia. The traders tend to under-react to the information arrival. The results provide qualified support for Debondt and Thaler (1985) investor overreaction theory.

Chinese and Australian stocks exhibit variation in their speed of adjustments, indicating the prominent role of firm-specific factors in the price adjustment process. This may be explained as being the result of inefficiency in the information dissemination process. Traders are comprised of informed and uninformed traders. Informed traders have private information beyond the market information. Uninformed investors are limited to market information. Market information is generally shared by the informed and uninformed. Thus speed of adjustment due to market information will be faster than firm-specific information. Uninformed traders may observe the trading behaviours of informed traders for their investments decisions. There is evidence of asymmetries (Marisetty, 2003).

The results imply the speed of adjustment process in Chinese and Australian markets is very slow. This indicates inefficiencies in the information dissemination process. Due to the lack of private information uninformed investors may exhibit herd behaviour resulting momentum effects.

\section{Acknowledgements}

The author is supported by a Curtin University Postgraduate Scholarship and a Curtin Research Scholarship. The author would like to thank Professor John L. Simpson of the School of Economics and Finance at Curtin University for his comments and suggestions.

\section{References}

Amihud, Y., \& Mendelson, H. (1987). Trading mechanisms and stock returns: An empirical investigation/ discussion. Journal of Finance, 42, 533-555. http://dx.doi.org/10.1111/j.1540-6261.1987.tb04567.x

Ariff, M., \& Chan, D. (2002). Speed of share price adjustment to information. Managerial Finance, 28, 44-65. http://dx.doi.org/10.1108/03074350210768004

Barberis, N., Shleifer, A., \& Vishny, R. (1998). A model of investor sentiment. Journal of Financial Economics, 49, 307. http://dx.doi.org/10.1016/S0304-405X(98)00027-0

Bernard, V., \& Thomas, J. (1989). Post-earnings announcement drift: Delayed response or risk premium? Journal of Accounting Research, 27, 1-36. http://dx.doi.org/10.2307/2491062

Boulter, T. (2007). Speed of adjustment within currency markets. International Review of Business Research Papers, 3, 88-122.

Brisley, N., \& Theobald, M. (1996). A simple measure of price adjustment coefficients: A correction. Journal of Finance, 51, 381-382. http://dx.doi.org/10.1111/j.1540-6261.1996.tb05214.x

Damodaran, A. (1993). A simple measure of price adjustment coefficients. Journal of Finance, 48, 387-400. http://dx.doi.org/10.1111/j.1540-6261.1993.tb04716.x

Daniel, K. D., Hirshleifer, D., \& Subrahmanyam, A. (1998). Investor psychology and security market under- and overreactions. Journal of Finance, 53, 1839-1885. http://dx.doi.org/10.1111/0022-1082.00077

De Bondt, W. F. M., \& Thaler, R. H. (1985). Does the stock market overreact? Journal of Finance, 40, 793-805. http://dx.doi.org/10.1111/j.1540-6261.1985.tb05004.x

De Bondt, W. F. M., \& Thaler, R. H. (1987). Further evidence of investor overreaction and stock market seasonality. Journal of Finance, 42, 557-581. http://dx.doi.org/10.1111/j.1540-6261.1987.tb04569.x

Fama, E. (1998). Market efficiency, long term returns and behavioural finance. Journal of Financial Economics, 49, 283-306. http://dx.doi.org/10.1016/S0304-405X(98)00026-9

Hong, H., \& Stein, J. C. (1999). A unified theory of underreaction, momentum trading and overreaction in asset markets. Journal of Finance, 54, 2143-2184. http://dx.doi.org/10.1111/0022-1082.00184

Jang, J. (2009). The dynamics of market efficiency. Job Market Paper, State University of New York (SUNY) at Buffalo.

Jegadeesh, N., \& Titman, S. (1993). Returns to buying winners and selling losers: Implications for market efficiency. Journal of Finance, 48, 65-91. http://dx.doi.org/10.1111/j.1540-6261.1993.tb04702.x

Jegadeesh, N., \& Titman, S. (2001). Profitability of momentum strategies: An evaluation of alternative explanations. Journal of Finance, 56, 699-720. http://dx.doi.org/10.1111/0022-1082.00342 
Lo, A. W., \& MacKinlay, A. C. (1990). An econometric analysis of nonsynchronous trading. Journal of Econometrics, 45, 181-211. http://dx.doi.org/10.1016/0304-4076(90)90098-E

Marisetty, V. B. (2003). Measuring productive efficiency of stock exchanges using price adjustment coefficients. International Review of Finance, 79-99. http://dx.doi.org/10.1111/j.1369-412X.2003.00044.x

Michaely, R., Thaler, R. H., \& Womack, K. (1995). Price reactions to dividend initiations and omissions: Overreaction or drift? Journal of Finance, 50, 573-608. http://dx.doi.org/10.1111/j.1540-6261.1995.tb04796.x

Theobald, M., \& Yallup, P. (2004). Determining security speed of adjustment coefficients. Journal of Financial Markets, 7(1), 75-96. http://dx.doi.org/10.1016/S1386-4181(02)00068-X

\section{Copyrights}

Copyright for this article is retained by the author(s), with first publication rights granted to the journal.

This is an open-access article distributed under the terms and conditions of the Creative Commons Attribution license (http://creativecommons.org/licenses/by/3.0/). 